\title{
O QUE LÊEM OS CLÁSSICOS: INCLUSÕES, EXCLUSÕES E CONSTRUÇÕES CANÔNICAS
}

\author{
Benito Martinez Rodriguez ${ }^{*}$
}

Para poder ler os clássicos, temos de definir "de onde" eles estão sendo lidos, caso contrário tanto o livo quanto o leitor se perdem numa nuvem atemporal. Assim, o rendimento máximo da leitura dos clássicos advém para aquele que sabe alterná-la com a leitura de atualidades numa sábia dosagem.

Italo Calvino

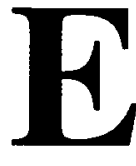

m crônica intitulada "O Nobel de Pessoa", 1 o crítico lusitano Arnaldo Saraiva pergunta-se, cheio de espanto: "Como foi possível que Pessoa se equivocasse tanto a respeito do seu 'candidato' ao Prêmio Nobel?" A escolha surpreendente do mestre português, informa-nos o crítico, era um poeta brasileiro. Segundo teria confessado a Carlos Queirós, em 1932 ou

* Universidade Federal do Paraná

1 Diário de Noticias, 8 mar 1994, p. 8. Fica registrada a minha gratidão à colega Anamaria Filizola, a quem devo a preciosa referência a esta crônica, bem como gentileza da cópia de seu original. 
1933, Pessoa entendia que, em nossa língua, "o único poeta vivo cuja obra, com os seus evidentes defeitos, correspondia às condições fundamentais" para alcançar tal premiação era Catulo da Paixão Cearense.

À primeira vista, são abundantes as razões para desconfiarmos de tal juízo pessoano. Afinal, ele chega até nós filtrado pela memória de seu interlocutor, num relato publicado bem mais de uma década depois de alegadamente ter sido enunciado, e muito tempo após o próprio desaparecimento de seu suposto autor. Ainda que não coloquemos em questão a veracidade do relato de Carlos Queirós, podemos, como assinala o próprio Arnaldo Saraiva, especular que ele tivesse tomado "a sério o que poderia ser uma boutade ou uma 'provocação' de Pessoa, que não deveria conceder grande importância ao Prêmio Nobel". Mas é o próprio professor Saraiva quem desmonta estas últimas hipóteses ao demonstrar, apoiando-se em outros textos pessoanos, que Catulo era tido por ele, de fato, na conta de "grande poeta"2.

Não é o caso de discutir-se a ligeireza com a qual Arnaldo Saraiva comenta a obra do poeta brasileiro, o que a natureza de seu texto, uma crônica publicada na imprensa diária, por si só torna compreensível ${ }^{3}$. O espanto que the provocam as simpatias pessoanas por tão obscuro autor, isto sim, merece alguma reflexão.

A reação do crítico parece trair o pressuposto de que aos mestres só devessem interessar, e mais ainda, cativar, as obras de seus pares. A idéia de que os diferentes circuitos de produção e circulação da cultura e da arte estariam separados uns dos outros e definidos de maneira mais ou menos clara, pode ser bastante enganosa, especialmente quando posta no contexto de nosso século.

2 "Numa breve passagem de um texto em inglês que Teresa Rita Lopes acaba de revelar no seu Pessoa inédito ... se diz que Catulo Cearense é um grande poeta (great poet) que 'dramatiza os seus poemas no patois do sertão brasileiro'." Saraiva acrescenta, a seguir, que "já antes tivera acesso a outro inédito onde comparece o nome de Catulo da Paixão Cearense, sem mais, ao lado do nome de Camilo Pessanha e de outras indicações" num projeto editorial de tradução para o inglês de textos de autores em língua portuguesa. Para confirmar definitivamente o "intrigante fascínio" do poeta português por seu colega brasileiro, transcreve os versos da série de poemas sobre os santos populares que vieram à luz em 1986, em edição preparada por Alfredo Margarido, onde São João aparece " "Com o cordeirinho na mão', / Como te viu Catulo Cearense". A citaçāo no verso pessoano refere-se ao famoso poema "O marroeiro", incluído no volume $M e u$ sertão (1918), do poeta brasileiro.

3 Os comentários sobre Catulo da Paixão Cearense, embora restritos à fração mais conhecida de sua obra literária, são em linhas gerais adequados. $O$ mesmo já não se pode dizer da infeliz observação sobre a peculiaridade de haver mais de um autor brasileiro homônimo de grandes mestres, citando, a título de blague, $o$ bom poeta Dante Milano. 
Trata-se aqui, já se vê, de uma das ramificações do tema formulado por Andreas Huyssen como "the Great Divide"4.

O professor Saraiva reconhece em sua crônica que os volumes de poesia que Catulo Cearense passou a publicar a partir de 1918 e durante a década seguinte "comoviam a gente popular e culta com a sua suposta ingenuidade e espontaneidade, que a grafia fonética mais acentuava, ou com a sua pretensa visão do mundo sertanejo e caipira, tão reconfortante para um público urbano que assistia à invasão das tecnologias mecânicas". Acrescenta, ainda, que seus textos "não só eram editados com sucesso mas também eram contados ou recitados por todo o Brasil (e Portugal!), onde produziram inúmeras imitações".

De fato, Catulo Cearense, na altura em que Fernando Pessoa o teria recomendado para o Nobel, andava na casa dos 70 anos de idade, tendo, com sua obra, realizado um percurso bastante mais intrigante do que o mote da crônica citada.

\section{Civilizando a modinha}

Tendo iniciado sua vida artística no final do Império, como violonista, cantor e letrista dos gêneros seresteiros da época, sobretudo da já declinante modinha, Catulo foi conquistando a simpatia do público suburbano e o respeito de seus colegas das rodas de choro ao longo dos últimos anos do século 19. Em ambos os casos, seu prestígio baseava-se nos talentos de músico. Mas, sobretudo, na superioridade relativa de sua cultura letrada, num meio onde o domínio do francês, conhecimentos de latim e rudimentos de italiano e inglês, faziam daquele chorão o mestre da linguagem a que muitos recorriam para a revisão de suas criações.

Muitos anos mais tarde, em 1935, Alexandre Gonçalves Pinto, um companheiro dos velhos tempos, planejando publicar seu livro de reminiscências sobre a vida musical popular do Rio de Janeiro das décadas passadas, ainda recorreria a Catulo, enviando-lhe os originais na esperança de conseguir, além do prestígio de um prefácio, a gentileza de uma revisão gramatical ${ }^{5}$.

4 HUYSSEN, Andreas. After the Great Divide: Modernism, Mass Culture, Postmodernism. (introduction). p. 8.

5 Trata-se de $O$ choro: reminiscências dos chorōes antigos, publicado, afinal, no ano seguinte. O livro estampa a resposta de Catulo aos pedidos do autor, em breve carta datada de 28/10/35. Desculpando-se por não poder prefaciá-lo, o veterano mestre observa que apenas uma revisão geral poderia corrigir os originais, que já estando prontos para a edição, tornavam impossível a empreitada. Ary Vasconcelos, pesquisador responsável pela reedição fac-similar deste livro em 
A coleção Cancioneiro popular de modinhas brasileiras, organizada por Catulo Cearense para a Livraria Quaresma originalmente em 1899, inclui na sua $25 .^{\text {a }}$ edição, de janeiro de 1908 , um breve preâmbulo de três páginas, intitulado "Algumas palavras":

Desculpe-me o leitor; sou forçado a pedir-lhe a benevolência de ler estas palavras em amplo desalinho, porque, talvez, seja um dos que me anatematizem, não as lendo. A instâncias dos Srs. Quaresma \& C., pude, com trabalho ímprobo, colecionar algumas das mais belas modinhas e corrigi-las, pois confesso que não experimentei o prazer de me vir às mãos uma só que fosse, a qual não contivesse as mais bárbaras e repugnantes incorreções.

Eis porque digo que esse trabalho de corrigir o que está eivado de erros crassos é ímprobo, e, o que mais é, de suma responsabilidade.

Explico-me. Desejando incluir n'este volume uma qualquer modinha, que, por ser bela e popular, preenche os dois fins primordiais, depois de muito procurar, chega-me às mãos quase inteiramente estropeada. Não conhecendo o seu autor, que me é dado fazer?

Corrigi-la gramaticalmente, ligar o pensamento desconexo, cuidando também um pouco da parte métrica, de modo a não ficar um aleijão, impiamente ferindo o ouvido educado.

Por isso peço perdão a todo o poeta que deparar n'este volume com alguma composiçāo sua, a qual não esteja como lhe gotejou da pena.

Se o conhecesse, tê-lo-ia procurado, a fim de fazer as correções que the aprouvesse.

Quanto às poesias de minha lavra, nada direi. Tivesse eu talento, ilustração e estro, e dedicar-me-ia, de corpo e alma, a esse gênero de literatura, o mais profícuo de todos.

Nós, os amadores afervorados das langorosas modinhas brasileiras, acompanhadas aos harpejos de um violão soluçante, plangendo pelas caladas de uma noite branca e silenciosa; nós, convencidos de que nessas composições do povo cintilam fulgurantes pensamentos que, raríssimas vezes, são lobrigados nas

1978, assim se referiu à obra: "poucos livros já lançados em todo o mundo foram tão mal escritos e tão massacrados por uma tipografia [...], para não falar na revisão, que certamente nem sequer existiu". O volume, preciosíssimo pelas informaçōes que nos transmitiu de todo um ambiente da vida cultural carioca dos fins do século 19, documenta ainda os motivos da óbvia ascendência de Catulo Cearense sobre seus parceiros do passado, cuja formação educacional mal chegava às primeiras letras. 
obras da alta literatura; nós, que preferimos uma modinha, uma canção rústica, um lundu requebrado a um qualquer trecho de Wagner, que não compreendemos e que não nos produz a mínima sensação... não nos importamos com o pedantismo estulto dos que menoscabam do violão, por ser ele, dizem, o instrumento dos 'desocupados e perdidos'. Quando encontrardes um desses tipos numa sala em que haja alguém que vos deseje ouvir, recitai com ênfase e entusiasmo a poesia que dediquei ao violão, e, depois, cantai a modinha que se segue a essa poesia, mas, é a única coisa que vos peço, com todo o sentimento! Quando proferirdes os nomes de Aureliano Lessa, Bernardo Guimarães, Laurindo, Varela, Castro Alves e Tobias Barreto, principalmente, fitai com veemência os minguados paspalhões, e deixai-os eclipsados na imensidão de suas insignificantes pessoas. Esses gênios superiores eram sinceros adoradores do violão. $O$ conselheiro Otaviano, dizia que, ao sair do Lírico de onde vinha saturado de música clássica, e, ao passar pela casinha de um pobre trovador, parava extasiado, ouvindo, os suspiros da sua voz dolente e os gemidos do seu violão, harmonioso e terno. Concluo, lamentando não ver neste volume, o que seria um trabalho colossal, todas as nossas ternas, meigas, doces e saudosas modinhas brasileiras, preciosíssimas jóias do escrínio do estro popular. Mas, ainda assim, os Srs. Quaresma \& C., vão prestando conscientemente, inestimável serviço à litcratura mais nacional - a do povo.

Janeiro de 1908

Já se vê que o autor/compilador, por essa época, para fazer a defesa de "nossas ternas, meigas, doces e saudosas modinhas brasileiras", julga necessário defini-las como "preciosíssimas jóias do escrínio do estro popular". Trata-se de responder "ao pedantismo estulto dos que menoscabam do violão, por ser ele, dizem, o instrumento dos desocupados e perdidos", com um esforço de hipercorreção, a um tempo, ingênuo e estratégico. Extração cultural e condição de classe combinam-se para atacar o gênero da preferência de Catulo. Determinado a superar ambas as barreiras, ele busca ampliar o espaço e as audiências para a modinha cortejando o gosto de seus detratores e exibindo uma hiperbólica proficiência nos modelos literários consagrados. Animador musical dos salões de certas eminências do Império e da República Velha, Catulo alcançaria o ápice ${ }^{6}$ de sua carreira musical neste ano de 1908, apresentando-se

6 A busca da ascensão social e artística de Catulo da Paixão Cearense inspiraria Lima Barreto na composicão da personagem Ricardo Coração dos Outros, no romance Triste fim de 
RODRIGUEZ, B. M. O que lêcm os clássicos: inclusōes...

no Instituto Nacional de Música, naquele que foi o primeiro concerto de violão popular realizado no auditório da vetusta instituição.

Por essa época, Catulo ainda era visto por setores das elites culturais como uma espécie de curiosidade bizarra. Em crônica famosa, João do Rio assim o descreve:

[Ele é] o último trovador velho-gênero, é o esteta da trova popular. Vê-lo recitar "O poeta" e "A fidalga", com um copo de chope na mão, é um desses espetáculos de brasserie inesquecível. Catulo emaranhou-se no dogma da moda, corrigiu versos de tudo quanto era quadra, estudou Bellini, Donnizetti, Verdi, adaptou os nossos versos a trechos de óperas e, finalmente, compôs traduções livres de Leconte de Lisle para serem recitadas ao piano! ${ }^{7}$

O cronista arguto aponta o terreno problemático no qual transita o artista. Representante de uma tradição popular em franco declínio, Catulo esforçava-se em adaptar seus trabalhos e interpretações às modas dominantes da alta cultura. Contudo, a defasagem cronológica e de classe não parecia produzir senão um resultado burlesco.

Anos mais tarde, em 1918, o mesmo cronista escreveria: "Há quinze anos eu tremi de cólera vendo Catulo cantar ao violão, traduzidos por ele, versos de Leconte. De repente, porém, esse homem, que é um gênio natural, conseguiu escapar à tolice urbana". 8

Quem teria mudado, afinal? O crítico ou o criticado?

\section{Mas ele não está tocando...}

De alguma maneira ambos. E, sobretudo, o cenário cultural. A essa altura, Catulo da Paixão Cearense já abandonara as serestas de rua e mesmo a composição e interpretação de modinhas com suas letras à moda parnasiana. Envere-

Policarpo Quaresma, cujas anotações originais datam de 1910 e a redação completa se faz nos primeiros meses de 1911. Os limites de tal projeto são admiravelmente representados no destino da personagem.

7 RIO, João do [Paulo Barreto]. A alma encantadora das ruas. Rio de Janeiro: Secretária Municipal de Cultura, Departamento Geral de Documentação e Informação Cultural, 1995. p. 179.

8 Crônica publicado em $O P a l s$, Rio de Janeiro, 28 dez. 1918, e reproduzida parcialmente na quarta edição de Um boêmio no céu, p. 201-207. 
dando pelo terreno das toadas sertanejas, conheceria seus pontos mais altos nesse filão entre 1912 e 1915, especialmente após o seu contato com o importantíssimo violonista João Teixeira Guimarães, que ganharia a posteridade como João Pernambuco, de quem muitos afirmam ter Catulo roubado a melodia de seus maiores sucessos no gênero: "Cabocla de Caxangá" e "Luar do Sertão".

Mas Catulo Cearense já não pretendia ser conhecido apenas como um letrista de modinhas ou toadas. A segunda crônica de João do Rio viera à luz ainda sob o impacto da publicação de seu primeiro volume de "poesia sertaneja": Meu sertão. A festa de lançamento, no Teatro São Pedro, contara com a presença de ministros da República (Pedro Lessa), deputados (Miguel Calmon), membros da Academia Brasileira de Letras (Alberto de Oliveira, Mário de Alencar), personalidades da imprensa (Assis Chateaubriand), da alta sociedade carioca e até do embaixador de Portugal.

Já não se tratava de uma coletânea de modinhas ou canções populares como as que ele reunira em tão bem sucedidas edições pela Livraria Quaresma. Era seu volume de estréia no gênero dos poemas narrativos de acento sertanejo, ou melhor, escritos na "grafia fonética [com que afirmava] sua pretensa visão de mundo sertanejo e caipira", na correta definição, antes citada, de Arnaldo Saraiva. Note-se que, embora nascido no Maranhão, e tendo passado a infância no Ceará (de onde herdou o epíteto transformado em apelido familiar), Catulo viveu mais de 65 anos no Rio de Janeiro. Daí, como ele próprio confessaria, sem qualquer pudor ou modéstia: "O meu grande mérito está nisso: em não conhecer o sertão e descrevê-lo tão admiravelmente". 9

$\mathrm{O}$ velho Catulo parecia empolgar precisamente às parcelas da elite literária que estavam à beira de serem suplantadas pela vanguarda modernista. Seu caminho penosamente percorrido em busca de uma inserção no território da alta cultura carioca e nacional, desde a freqüência aos salōes familiares de Melo Morais Filho, até a simpatia de Rui Barbosa e Alberto de Oliveira, completava-se tarde demais. Em breve, uma nova geração de artistas entraria em cena, desmantelando precisamente os padrões estéticos aos quais ele esforçadamente se adequara. Decidido a transcender à escala e ao circuito populares, onde brilhara no passado, Catulo viveria o resto de seus dias apegado a modelos retardatários de valor e expressão literários.

Após o aparecimento de seus primeiros livros, entre 1918 e 1921, seu declínio, que foi o declínio do gênero que ele tencionara forjar, seguiu contínuo e irreparável. Ele viveria para amargurar-se com essa decadência de seu prestígio por mais de duas décadas, destilando seu rancor em patéticos prefácios aos seus

9 SILVEIRA, Joel. Tempo de contar. 3. ed. Rio de Janeiro: J. Olympio, 1993. p. 318. 
volumes novos ou reedições, cada vez mais indiscerniveis entre si, atacando a nova literatura e a decadência da canção popular brasileira.

Figura de fronteira, transitando precariamente entre registros populares e eruditos, a imagem inicial que João do Rio nos deu de Catulo Cearense continuaria adequada para descrever-lhe a condição a partir dos anos 20 .

A decadência da modinha como gênero de canção popular a partir da primeira década do século 20 era inevitável. Conscientemente ou não, ao buscar afastar-se do gênero, Catulo tentava sobreviver no cenário da produção cultural. O abandono da canção, contudo - embora inevitável, já que com mais de 50 anos de idade, sua voz já não dava conta da interpretação operística que dominava a cena -, foi-lhe fatal.

Orestes Barbosa, em crônica de 1923, escreve que "quando ele [Catulo] aparece sem violão ninguém gosta. Já vi o povo correr para um teatro a ouvi-lo e ficar triste. 'Mas ele não está tocando...', dizia-me isto um mulato pachola condutor de trem da Central". ${ }^{10}$ Outro depoimento precioso a esse respeito pode ser colhido em crônica de Manuel Bandeira a propósito do velório de Zeca do Patrocínio, o filho do tigre da Abolição, morto em 1929. Conta o poeta que estando certa vez na companhia de Villa-Lobos, Jaime Ovalle, João Pernambuco e Catulo, todos muito bêbados, o velho modinheiro animou-se a recitar versos. Escreve Bandeira:

Nós queriamos que ele cantasse umas modinhas, bem bestas, bem pernósticas, como "A Tua Formosura", ou "Clélia, Adeus!", ou "Talento e Formosura". Mas o bardo estava em maré de grandeza e dizia muito sério a duas belezas venais: "Minhas senhoras, eu tenho sessenta anos e já li todos os poemas de todas as literaturas; li todo o Homero, todo o Virgílio; li Goethe, Shakespeare, Ariosto: nunca encontrei nada como este poema da minha lavra que vou thes recitar!". Quando ele puxava o pigarro para começar e a versalhada parecia inevitável, o Zeca salvava a situação: "Ó Catulo, canta aquela modinha!"11

As novas formas de canção popular urbana, veiculadas de maneira cada vez mais sistemática e massiva através dos fonógrafos e gramofones, do teatro

10 BARBOSA, Orestes. O violão. In: Bambambã. 2. ed. Rio de Janeiro: Secretaria Municipal de Cultura, Departamento Geral de Documentação e Informação Cultural, 1993. p. 98.

11 BANDEIRA, Manuel. Crônicas da Província do Brasil. Rio de Janeiro: Civilização Brasileira, 1937. p. 104. 
de revista e por fim, do rádio, consagrariam novos gêneros de canção, com ritmos e letras cada vez mais distantes das modinhas "aparnasianadas" do velho Catulo.

Num dos prefácios em que tencionava ajustar contas com sua época, escrito já na década de 40 , o veterano autor manifestava seu rancor diante das novidades:

Hoje, no Brasil, polulam [sic] os "bardos nacionais" e nenhum deles deixa de compor sua marchinba, seu samba ou sua canção, falando sempre na "cabocla", no "malandro", no "Brasil pandeiro", nome este acapadoçado, que até melindra a nossa brasilidade. Os célebres trovadores, não sei porque, fizeram dos morros o seu Parnaso, esses lugares evitados em outros tempos por todas as pessoas decentes. Os morros, com os seus desordeiros e os seus assassinos nos apavoravam! Hoje são aclamados por senhoras e senhores da alta nobresa [sic]!!! Basta que um sujeito escreva um samba, em que, capadoçalmente, fale em Brasil, para que logo seja considerado um poeta de vôos nacionais. Agora, tudo é Brasil, Brasil, Brasil, e, no entanto, há 50 anos, quando eu já dedicava os meus descantes ao Brasil brasileiro, era chamado de maníaco, porque só cantava a minha pátria".

Condenado por sua longevidade a acompanhar a perda progressiva de espaço e respeitabilidade tanto no círculo dos artistas populares, onde os antigos chorões, quase todos desaparecidos, tinham cedido lugar para os sambistas, quanto no quadro da nova ordem da cultura letrada, Catulo veria também seu público, em ambos os casos, desertar para as novas formas e gêneros. "Passei de moda, é verdade!", 13 ele próprio melancolicamente admitiria.

\section{Gregos e troianos no sertão cearense}

A despeito do anacronismo estético de suas opções, da superficialidade estilística de sua adesão às técnicas do momento, da precariedade de sua reflexão sobre a arte de seu tempo, além da absoluta incapacidade para o exercício sincero

12 CEARENSE, Catulo da Paixão. Uma palestra com os leitores. In: $O$ milagre de São João. Rio de Janeiro: A Noite, [1942?]. p. 7.

13 Ibid., p. 12. 
RODRIGUEZ, B. M. O que lêcm os clássicos: inclusões...

da autocrítica, Catulo da Paixão Cearense conseguiu despertar a atenção e até a simpatia de figuras relevantes ao longo de sua longa vida.

Se João do Rio o trataria como "gênio natural", em 1918, um dos grandes desafetos do cronista das ruas cariocas, o escritor Lima Barreto, assim se referiria a Catulo em texto de 1922:

O violão e a modinha que Catulo, com a sua tenacidade, com o seu talento e a sua obediência cega a um grande ideal, dignificou e tornou capaz da atenção dos intelectuias, vão sendo mais prezados e já se fazem encantos dos saraus burgueses, em que, pelas causas apontadas, as danças mínguam. É pena que para um Catulo, artista honesto, sob todos os pontos de vista, haja uma dezena de Casanovas disponíveis, que, maus de natureza e sem talento algum, se servem da arte reabilitada pelo autor de "Sertanejo", a fim de, por intermédio de horríveis cantarolas, levarem a desgraça a lares pobres e perder moças ingênuas $\mathbf{e}$ inexperientes.

Vale assinalar o descompasso entre o gosto musical de Lima Barreto e as novas formas musicais em amplo desenvolvimento na época. ${ }^{15}$ De fato, nesta crônica o romancista parece aproximar-se, com atraso de mais de uma década, da simpatia ingênua que nutria pelas modinhas o seu Policarpo Quaresma. Naquele romance, as esperanças de ascensão social e artística do mestre das modinhas Ricardo Coração dos Outros, tipo francamente inspirado em Catulo, frustram-se com a deflagração da Revolta da Armada. Ao ser integrado às tropas florianistas, Ricardo, que pouco antes alcançara respeitabilidade e livre trânsito pelos salões da burguesia suburbana, vê-se rebaixado para a condição de soldado raso. A farda, somada à sua adesão ao amigo caído em desgraça, revelam os limites deste projeto de ascensão individual, fundado em moedas fracas como o mérito pessoal e a camaradagem entre elementos de diferente extração social.

Como cancionista, Catulo poderia interessar a um Villa-Lobos, que dele diria ter-lhe sido "mais útil que o próprio Ernesto Nazareth" " assim como a

14 BARRETO, Lima. Bailes e divertimentos suburbanos. In: Marginália. São Paulo: Brasiliense, 1956. p. 66.

15 Discuto com detalhes este tema em minha dissertação de mestrado, Duelo ou dueto: a indecisa posição frente ao mundo moderno em Clara dos Anjos, de Lima Barreto, São Paulo, 1992.

16 Depoimento transcrito em Poemas escolhidos, p. 22. Ademais, basta lembrar que a camaradagem entre Villa-Lobos e Catulo era tamanha, que, além de resultar em muitas noitadas de seresta no Rio Antigo, veio a dar em adaptações de peças deste em formato erudito pelo maestro. A mais célebre destas "colaboraçōes" foi a inclusão, no "Choro n. 10", de "Rasga Coração", chótis 
José Barbosa da Silva, o Sinhô, auto-proclama" dos anos 20, que irritadíssimo com o prestígio que imaginava gozarem Villa-Lobos e Catulo Cearense, confessava sua lisonjeira inveja para o atento Manuel Bandeira, em 1929: "[Sinhô] espinafrava tudo quanto era músico e poeta, estava danado naquela época com o Vila[-Lobos] [sic]e o Catulo. Poeta era ele, músico era ele".'

Outro autor a revelar vigoroso interesse por Catulo, embora fosse um dos responsáveis pelo desmoronamento dos referenciais estéticos dele, foi o mestre modernista Mário de Andrade. Em crônica no Diário Nacional, datada de 20/12/1931, Mário faz uma reavaliação do conjunto da obra de Catulo Cearense, incluindo aí a porção como letrista de modinhas, além da fase de toadas sertanejas e a poesia em livro até aquele momento, concluindo, não sem uma dose de tristeza:

Catulo Cearense foi sublime no $\mathrm{Meu}$ Sertão como poeta urbano e culto, aceitando poetar dentro da corrente regionalista. Até esta aceitação da escola literária, no modinheiro e maxixeiro contumaz da Corte, era fenômeno exclusivo de civilização. Mas esta civilização era falsa, importada. Deu um brilho momentâneo fulgurante pro pobre do brasileiro, mas foi corroendo, corroendo ele por dentro, deformando-o, nulificando-o. Os últimos livros de Catulo não são nada. ${ }^{18}$

Cinco anos antes, porém, Mário de Andrade revelaria, em correspondência a Manuel Bandeira, o grau do interesse que aquela poesia, então ainda saborosa, era capaz de lhe provocar:

As poesias, estou mais ou menos de acordo com você mas me parece difícil de mudar certas coisas. A parecença com Catulo [Cearense], por exemplo. Não tem dúvida que existe porém não pretendo modificar isso. Não é a única vez que imito Catulo. $E$ que me importa que pareça com o torneio de estilo dele, o pedacinho. "Um aboio tão sentido", etc. Acho essa idéia linda, do aboio acuar dentro da gente o "sono brasileiro". Engraçado que quando você citou o "canteiro de barboletas" achei isso feio.

de Anacleto Medeiros, com letra de Catulo Cearense, o que degeneraria numa lamentável disputa por direitos autorais na década de $\mathbf{5 0}$.

17 BANDEIRA, op. cit., p. 104.

18 ANDRADE, Mario de. Catulo Cearense. In: Táxi e crônicas do Diário Nacional. São Paulo: Duas Cidades/Secretaria da Cultura, Ciência e Tecnologia, 1976. p. 177. 
Em geral as metáforas me desagradam agora, estou fatigado de imagens assim creio que vou tirar isso, porém só porque acho feio. Lembre-se aliás daquele seu conselho justo de que devemos imitar para fixarmos alguma coisa brasileira. E Catulo seja falso como falam, seja bem sertanejo, o certo é que é inconfundivelmente brasileiro como psicologia e como dicção, é ou não é! ${ }^{19}$

O autor refere-se ao seu poema "Lenda do céu", incluído em Clã do Jabuti. O trecho mencionado foi de fato mantido, apenas com a substituição de uma palavra, "um aboio tão chorado / que acuava no corpo doce / o sono do brasileiro". O reconhecimento que Mário de Andrade faz, nesta altura de sua carreira, do interesse que a "dicção" de Catulo lhe desperta, vai ao limite da franca emulação.

\section{O que lêem os clássicos}

Como se viu, a recepção da obra de uma personalidade artística como Catulo da Paixão Cearense é muito mais eclética do que poderia supor o crítico Amaldo Saraiva. Evidentemente, não é o caso de sustentar o merecimento de uma indicação ao Nobel para este poeta. O ponto em questão é o reconhecimento de que, um conjunto híbrido e extenso como o seu, realizado no decorrer de profundos processos de transformação da sociedade brasileira, fez-se em atrito, tensão, emulação, resposta ou adesão a muito do que veio a se cristalizar como tradição canônica, tanto na literatura, quanto na canção popular.

Como não perceber na vertente "lunar", 20 tão sedimentada pelas modinhas catulinas, um eco das composições de um Caldas Barbosa, que o precedeu, e de um Orestes Barbosa, que o sucederia com relevantes inovações nas décadas

19 Cartas a Manuel Bandeira, p. 106. A propósito da fortuna crítica de Catulo Cearense entre os modernistas, note-se que Manuel Bandeira inclui dois trabalhos do poeta em sua antologia Obras-primas da lírica brasileira, p. 145-147. Fernando Góes, já em 1960, também incluirá o célebre "Marruero" no Panorama da poesia brasileira, p. 116-125. Na apresentação ao autor, este crítico cita, sem referir a fonte, palavras de Sérgio Buarque de Holanda, que falaria da "surpresa, do encantamento e da comoção" que causariam os textos de Catulo Cearense.

20 Segundo a tradição, a primeira modinha composta por Catulo Cearense, em 1880, ano de sua chegada ao Rio de Janeiro, tinha por título "Ao luar". Ela não deve ser confundida com a composição "Ontem ao luar", polca de Pedro de Alcântara, na qual Catulo poria versos em 1913, transformando-se num de seus maiores sucessos. Para não falar no "Luar do sertão". Catulo Cearense nas vozes de Paulo Tapajós e Vicente Celestino, encarte do CD preparado por Abel Cardoso Jr., p. 3-4. 
de 30 e 40 ? Por essa via, na chamada linha evolutiva da música popular, seus efeitos seriam reelaborados por um Caetano Veloso tropicalista, em "Paisagem útil", quando a lua transforma-se em luminoso de uma companhia multinacional, e mesmo no mais que contemporâneo Djavan, de "Irmã de néon": "Entre beijos divinais / Uma mordida aqui / Outra ali / Cresce nos matagais o meu querer por ti // Perfumada flor de lã / Tua aragem me apraz e seduz / Cabelos, tantos pelos, tantos uis, ui // Monumento colossal / Musa com véu / A tal, a que diz / Como e porque merece ser a mais feliz / Eva, irmã de Néon...". 21 A adjetivação preciosa, a hiperbolização da beleza feminina, combinam-se de modo saboroso com o ritmo caribenho da melodia. Nesta altura, o luar já se transformara definitivamente em néon.

No campo da cultura letrada e erudita, é possível perceber que Fernando Pessoa não estava solitário nas simpatias pelo poeta brasileiro, tampouco em companhia pouco prestigiosa. Mário de Andrade, Villa-Lobos, Sérgio Buarque de Holanda, se não chegaram a recomendar, até onde se sabe, o poeta "sertanejo" para prêmios literários, não deixaram de lê-lo com interesse, incorporando, no caso dos dois primeiros, aspectos da obra de Catulo às suas próprias realizações artísticas.

\section{O Nobel de 1933}

A lição que o episódio explorado pela crônica do professor Arnaldo Saraiva parece nos oferecer é a de que na sociedade moderna, a promiscuidade entre circuitos de (re)produção e recepção da criação artística é mais intensa do que nossas classificações retrospectivas nos querem fazer crer.

Portanto, antes que um desperdício, a leitura dos que ficaram à margem dos repertórios canônicos, abandonados ao pó dos sebos, às referências de rodapé, ou às anedotas da crônica literária cotidiana, pode lançar luz sobre uma vida literária muito mais rica, em seus anacronismos e desconexões, em suas simpatias ou antipatias inesperadas ou inexplicáveis, em sua mais prosaica, e viva, realização.

Ou na observação de Italo Calvino:

Talvez o ideal fosse captar a atualidade como o rumor do lado de fora da janela, que nos adverte dos engarrafamentos do

21 DJAVAN. Malásia, Épic, 1996, faixa 7. 
trânsito e das mudanças de tempo, enquanto acompanhamos o discurso dos clássicos, que soa articulado no interior da casa. ${ }^{22}$

$\mathrm{O}$ ano de 1933 parece ter sido pródigo em indicações discutíveis de autores de língua portuguesa para o Nobel. Além da menção de Pessoa a Catulo, a Academia Brasileira de Letras, "por aclamação", indicaria o nome de Coelho Neto. $^{23}$

Intrigante para o leitor de hoje, a sugestão de Pessoa, na época ainda muito longe de desfrutar do prestígio internacional que pudesse credenciá-lo como "eleitor" privilegiado do Nobel, pouco pode fazer pelo nome de nosso modesto Catulo. Nada surpreendente, já que também foi inútil a representacão unânime dos imortais de então em favor da opulenta obra de seu veterano companheiro de casa, que alcançara 273 edições em língua portuguesa, acrescida de um sem número de traduções para o francês, inglês, italiano, alemão, espanhol e japonês!

Como se sabe, nenhum autor de língua portuguesa foi, até hoje, agraciado com o Nobel de Literatura. Busco em meu almanaque a informação sobre quem teria roubado a nossos "candidatos", o polígrafo oficial e o oficioso vate sertanejo, a láurea naquele ano. Topo com Ivan Alexeiévich Bunn. Na enciclopédia mais próxima, busco remédio para minha crassa ignorância quanto ao poeta laureado. Um minúsculo verbete informa apenas que o poeta Ivan, aliás Bunin, segundo essa fonte, nasceu na Rússia em 1870, mas naturalizou-se francês. De sua extensa obra, os redatores da breve notícia de cinco magras linhas animaram-se a citar apenas uma tradução sua, para o russo, do poema Lady Godiva. Morreria vinte anos após roubar a chance de glória para nossos literatos.

Pessoa admirava Catulo. Catulo admirava Coelho Neto. E este, nutria enorme simpatia por seu conterrâneo maranhense. Tão diferentes na fatura e no percurso, as obras destes autores atravessaram o século 20 , a despeito da lenta aceitação do poeta português, ainda hoje em fase de redescobertas e espantos; e do franco declínio do interesse popular pelos dois autores brasileiros. ${ }^{24}$ Mais recentemente, experimenta-se um surto de releituras e reavaliações da produção que se realizou imediatamente antes e prosseguiu à sombra do modernismo.

22 CALVINO, Italo. Por que ler os clássicos, p. 15.

23 COELHO Neto, Paulo. Bibliografia de Coelho Neto. Rio de Janeiro: Bosoi, 1956. p. 11.

24 O último bastiāo da resistência destes dois no repertório popular foram os compêndios escolares, que até meados da década de 60 ainda os privilegiavam na seleção de textos. Ver LINS, Osman. Do ideal e da glória. Problemas inculturais brasileiros, p. 15-40. 
Como o Nobel não é outorgado postumamente, estamos livres do risco de se levantarem vozes na defesa de algum ajuste de contas histórico.

A propósito, será que alguém se lembra do premiado com o Nobel de Literatura em 1933?

\section{RESUMO}

Tomando como mote uma crônica literária do crítico português Arnaldo Saraiva na qual ele menciona a surpreendente simpatia de Fernando Pessoa pelo poeta e cancionista Catulo da Paixão Cearense, este artigo discute a complexa rede de relações articulada entre diferentes audiências e níveis de interlocução dentro dos quais a obra catulina se inscreveu. Desta maneira, evidencia-se a importância do exame da produção artística não-canônica para que se possa melhor compreender os mecanismos de construção, inserção e exclusão das séries canônicas.

Palavras-chave: Fernando Pessoa, Catulo da Paixão Cearense, tradição canônica.

\section{ABSTRACT}

Taking as a clue a newspaper literary column by portuguese scholar Arnaldo Saraiva, in which he mentions Fernando Pessoa's interest in Catulo da Paixão Cearense's works, this paper studies the complex network within which different audiences have interacted with Cearense's works. In this way, one reveals the relevance of reading non-canonical production in order to realize the processes through which literary canon is built.

Key words: Fernando Pessoa, Catulo da Paixão Cearense, literary canon. 


\section{REFERÊNCIAS BIBLIOGRÁFICAS}

ANDRADE, Mário de. Taxi e crônicas do Diário Nacional. Estudo de texto, introdução e notas de Telê P. A. Lopes. São Paulo: Duas Cidades / Secretaria da Cultura, Ciência e Tecnologia, 1976.

BANDEIRA, Manuel. Crônicas da Província do Brasil. Rio de Janeiro: Civilização Brasileira, 1937.

BARBOSA, Orestes. Bambambã. 2. ed. Rio de Janeiro: Secretaria Municipal de Cultura, Departamento Geral de Documentação e Informação Cultural, 1993.

BARRETO, Lima. Marginália. São Paulo: Brasiliense (Obras completas de Lima Barreto; X), 1956.

Triste fim de Policarpo Quaresma. São Paulo: Brasiliense (Obras completas de Lima Barreto; II), 1956.

CALVINO, Italo. Por que ler os clássicos. Trad. de Nilson Moulin. São Paulo: Cia das Letras, 1993.

CEARENSE, Catulo da Paixão. O milagre de São João. Rio de Janeiro: A Noite, [1942?]. . Poemas escolhidos. 5. ed. Rio de Janeiro: Império, [s.d.].

Um boêmio no céu. 4. ed. Rio de Janeiro: A Noite, [1946].

COELHO NETO, Paulo. Bibliografia de Coelho Neto. Rio de Janeiro: Borsoi, 1956.

GÓES, Fernando. Panorama da poesia brasileira. Rio de Janeiro: Civilização Brasileira, 1960 , v. 5.

HUYSSEN, Andreas. After the Great Divide. Modernism, Mass Culture, Postmodernism. Bloomington: Indiana University Press, 1986.

LINS, Osman. Do ideal e da glória: problemas inculturais brasileiros. 3. ed. São Paulo: Summus, 1977.

PINTO, Alexandre Gonçalves. $O$ choro. Reminiscências dos chorões antigos. Rio de Janeiro: Funarte (MPB Reedições; 1), 1978.

RIO, João do [Paulo Barreto]. A alma encantadora das ruas. Rio de Janeiro: Secretaria Municipal de Cultura, Departamento Geral de Documentação e Informação Cultural, 1995.

RODRIGUEZ, Benito Martinez. Duelo ou dueto: a indecisa posição frente ao mundo moderno em Clara dos Anjos, de Lima Barreto. São Paulo, 1992. Dissertação Mestrado - Faculdade de Filosofia, Letras e Ciências Humanas, Universidade de São Paulo.

SARAIVA, Arnaldo. O Nobel de Pessoa. Diário de Notícias, 8 mar. 1994, p. 8. SILVEIRA, Joel. Tempo de contar. 3. ed. Rio de Janeiro: J. Olympio, 1993. 


\section{Discos citados}

CATULO da Paixão Cearense nas vozes de Paulo Tapajós e Vicente Celestino. Encarte preparado por Abel Cardoso Jr. Revivendo, [s.d.].

CARDOSO JR., Abel. Catulo da Paixão Cearense nas vozes de Paulo Tapajós e Vicente Celestino. Revivendo, [s.d].

DJAVAN. Malásia, Epic, 1996.

VELOSO, Caetano. Caetano Veloso, Philips, 1968. 